\title{
Mycological Features of Trichophyton verrucosum Isolated in Cattle
}

\author{
Su Jung Kim ${ }^{\dagger ; *}$ \\ Department of Biomedical Laboratory Science, Daegu Health College, Daegu 41453, Korea
}

In this study, the author observed the fungal characteristics of $T$. verrucosum which is commonly known as the cattle ringworm fungus in the farms of Hoengseong, Gangwon-do. After isolating 20 strains of T. verrucosum from cattle, they were cultured on SDA, PDA media and the fungal characteristics were concluded through visual observation of the colonies, microscopic findings, hair perforation test and urease test. The size of the colonies cultured on SDA media at $37 \mathrm{C}$ was on an average $5 \mathrm{~mm}$ at 1 week, $33 \mathrm{~mm}$ at 2 weeks, $42 \mathrm{~mm}$ at 3 weeks and $58 \mathrm{~mm}$ after 4 weeks. Observing the characteristics of the colonies, 17 strains of T. album showing central bold radial folds, 2 strains of T. ochraceum having 1 throughout the colonies and 1 strain of $T$. discoides with rapid growth rate and gray-white cotton patterns were found. On microscopic observations of the cultured colonies on SDA, PDA media, macroconidia and microconidia were not found in $T$. verrucosum and hyphae and chlamydospore were only seen in $T$. album types. Out of 20 strains of $T$. verrucosum, hair perforation test was positive on only 3 strains and urease test was positive on all of the 20 strains.

Key Words: Dermatophytoses, Zoophilic fungus, Trichophyton verrucosum

\section{서 론}

Trichophyton verrucosum 은 소에 버짐을 일으키는 피부 기생성 곰팡이며 각질을 분해하여 가피를 형성하고 인체 감염 시 두부백선을 유발하는 동물친화성 진균이다(Lee et al., 2018). 세계적으로 발생하는 T. verrucosum은 연령, 성별에 관계없이 발생하나 특히 생후 2 년 이하의 소에서 분리율이 높으며 소를 사육, 접촉, 그리고 도축업자들에 게 발생빈도가 높게 보고되었다(Shin et al., 1998; Zhan and Liu, 2017). 우리나라는 1977년 경상북도 금룽군의 한 한 우 목장에서 집단적으로 발생한 소 백선으로부터 처음 T. verrucosum을 분리하였고 사람에서의 감염은 1986년 전남 지역에서 한우로부터 전염된 두부 독창의 첫 예를 보고하였다(Choi et al., 1979; Kim et al., 1986). 사람의 $T$. verrucosum 감염은 대부분 소 백선으로부터 직접 감염되
는 것으로 잘 알려지고 있고 의복 등에 오염되어 가족에 게 전염시키는 중요한 매개체가 될 것으로 추측되며 주 로 얼굴, 팔, 몸, 두부 등의 순서로 발생한 것으로 보고했 다(Choi and Lee, 2006; Kim et al., 2006; Lee et al., 2018).

국내에서는 1992 년 김 등에 의해 소에서 분리된 $T$. verrucosum 의 역학적, 진균학적 소견을 발표한 이래로 $T$. verrucosum에 대한 발표가 전무하여 본 연구진은 소에서 분리된 T. verrucosum의 형태학적 성상을 조사하여 향후 동물친화성인 T. verrucosum의 분리에 있어 기초자료에 도 움이 되고자 실시하였다(Kim et al., 1992).

\section{재료 및 방법}

재료

2018년 01월부터 12월 31일까지 강원도 횡성에서 사육 하는 소 버짐 증상을 나타내는 소를 대상으로 소독된 압

Received: November 20, 2019 / Revised: December 5, 2019/ Accepted: December 9, 2019

* Professor.

†Corresponding author: Su Jung Kim. Department of Biomedical Laboratory Science, Daegu Health College, Youngsong-ro, Daegu 41453, Korea. Tel: +82-53-320-1303, Fax: +82-53-320-1450, e-mail: sjkim4238@hanmail.net

(C) The Korean Society for Biomedical Laboratory Sciences. All rights reserved.

(C) This is an Open Access article distributed under the terms of the Creative Commons Attribution Non-Commercial License (http://creativecommons.org/licenses/by-nc/3.0/) which permits unrestricted non-commercial use, distribution, and reproduction in any medium, provided the original work is properly cited. 
설자를 이용하여 각질, 가피, 그리고 피부를 수집하였으며 이런 검체를 Sabouraud dextrose agar (SDA), Potato dextrose agar (PDA)]와 urea dextrose agar를 이용하여 T. verrucosum 20균주를 분리하였다(Kim et al., 1992; Lee et al., 2018).

\section{방법}

육안적 소견: $\mathrm{SDA}$ 평판배지에 접종 후 $37^{\circ} \mathrm{C}$ 에서 배양하 고 집락의 가장 큰 직경을 매주마다 $\mathrm{mm}$ 단위로 측정하 여 4주까지의 성장 정도를 관찰하였고 배양 4 주째에 집 락의 전면을 관찰하여 형태에 따라 분류하였다(Lee et al., 2018).

현미경 검사: $\mathrm{SDA}$ 및 $\mathrm{PDA}$ 평판배지에 접종하고 $37^{\circ} \mathrm{C}$ 에 서 배양하여 접종 1 주부터 4주까지 scotch tape method로 집락의 표면을 채취, lactophenol cotton blue로 염색하여 현 미경하에서 관찰하였다. 또한 $37^{\circ} \mathrm{C}$ 에서 $\mathrm{SDA}$ 와 $\mathrm{PDA}$ 를 사용하여 slide culture를 실시하였다(Bang and Kim, 2007).

모발천공 검사: 모발은 멸균한 후 균주가 접종된 $\mathrm{SDA}$ 평 판배지에 뿌려서 배양 1 주와 2 주 후에 모발의 천공 여부 를 현미경으로 검사하였다(Hong et al., 2018).

Urea 시험: Uera dextrose agar에 접종 후 2주 동안 urea 분해 여부를 관찰하였다(Kim etal., 1992).

\section{결 과}

\section{육안적 및 현미경적 소견}

$37^{\circ} \mathrm{C}$ 에서 $\mathrm{SDA}$ 평판배지에 배양하여 관찰한 결과 성장
속도는 평균 균집락의 크기가 1주 3 8 mm(평균 $5 \mathrm{~mm}$ ), 2주에 20 45 mm(평균 $33 \mathrm{~mm}$ ), 3주에 30 55 mm(평균 $42 \mathrm{~mm}$ ), 그리고 4주 후에는 50 63 mm(평균 $58 \mathrm{~mm}$ )로 나 타났다(Table 1).

형태학적 특징을 관찰하기 위하여 $\mathrm{SDA}$ 평판배지에 소 에서 분리한 T. verrucosum 20 균주를 접종하여 4주간 배 양한 후 집락을 관찰한 결과 크게 3 가지로 나타났다.

1 형은 집락의 중앙부에서 시작되는 굵은 방사상의 주름 이 나타나며 주위로 뻗어 나가는 형으로 17균주(T. verrucosum var album)가 분리되었고 현미경 소견은 대분생자와 소분생자는 볼 수가 없었고 후막포자는 사슬모양의 전형 적인 염주형태가 많이 관찰되었다.

2형은 집락의 전반에 걸쳐 미세 주름이 나타나며 연한 황색의 집락으로 2 균주(T. verrucosum var ochraceum)가 분 리되었고 현미경 소견은 대분생자와 소분생자, 그리고 사 슬모양의 후막포자도 볼 수 없었고 균사의 말단부분에 단일상의 후막포자를 볼 수 있었다.

3형은 성장속도가 가장 빠르고 비교적 희고 편평하며 주름이 없는 원판형 집락이며 흰색의 솜털모양의 균사가 있는 형으로 1균주(T. verrucosum var discoides)가 분리되었

Table 1. Growth rate on Sabouraud dextrose agar at $37^{\circ} \mathrm{C}$

\begin{tabular}{ccc}
\hline \hline $\begin{array}{l}\text { Week after } \\
\text { inoculation }\end{array}$ & \multicolumn{2}{c}{ Size of colonies $(\mathrm{mm})$} \\
\cline { 2 - 3 } & Range & Mean \\
\hline 1 & $3 \sim 8$ & 5 \\
2 & $20 \sim 45$ & 33 \\
3 & $30 \sim 55$ & 42 \\
4 & $50 \sim 63$ & 58 \\
\hline
\end{tabular}
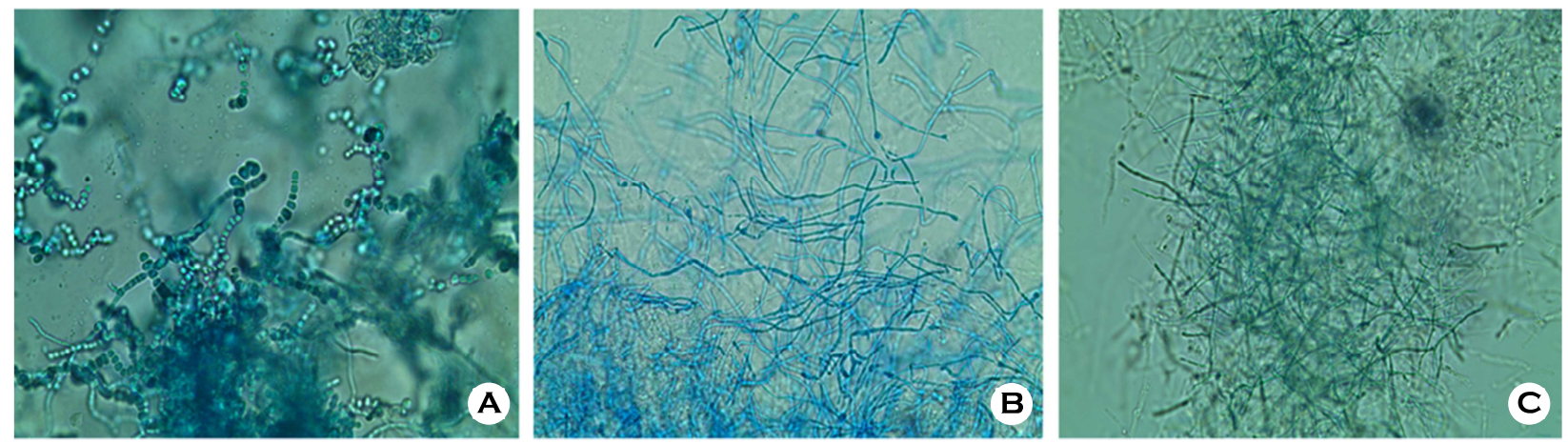

Fig. 1. Microscopic features of Trichophyton verrucosum (Lactophenol cotton blue, $\times \mathbf{4 0 0}$ Microscope). A: Type I, B: Type II, C: Type III. 
Table 2. Colony morphology on Sabouraud Dextrose Agar at $37^{\circ} \mathrm{C}$

\begin{tabular}{|c|c|c|c|}
\hline & \multicolumn{3}{|c|}{ T. verrucosum var } \\
\hline & $\operatorname{album}(\mathrm{n}=17)$ & ochraceum $(\mathrm{n}=2)$ & discoides $(\mathrm{n}=1)$ \\
\hline Color & Gray - white & Yellow & Gray - white \\
\hline Surface & $\begin{array}{l}\text { Flat, glabrous radial - folded } \\
\text { button like center }\end{array}$ & Flat and glabrous & Flat and cotton \\
\hline $\begin{array}{l}\text { Colony } \\
\text { morphology }\end{array}$ & & & \\
\hline
\end{tabular}

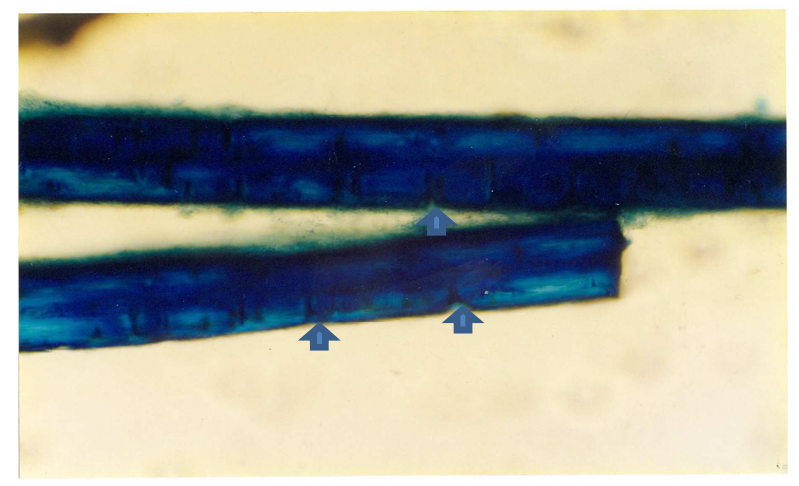

Fig. 2. Hair perforation test on SDA at $37^{\circ} \mathrm{C}$. Sites of hair perforation (arrow key, $\times 400$ Microscope).

다. 현미경 소견은 대분생자와 소분생자는 볼 수가 없었 고 균사가 풍부하며 사슬모양 후막포자는 볼 수 없었고 아주 드물게 단일상 후막포자를 볼 수 있었다(Fig. 1 \& Table 2, 3).

\section{모발천공 검사 및 urease 시험}

모발천공 검사는 $\mathrm{SDA}$ 배지에 균을 접종한 후 $37^{\circ} \mathrm{C}$ 에 서 배양하여 균사가 자라는 것을 확인한 후 소독된 모발 을 균사가 자라는 부위에 뿌려서 2주간 배양 후 관찰한 결과 총 20 균주 중 $17(85 \%)$ 균주에서 모발천공 반응 음성 이었고 $3(15 \%)$ 균주가 다발성의 모발천공 반응 양성을 확 인할 수 있었다(Fig. 2).

Urease 시험은 uera dextrose agar 사면배지에 접종 후 2 주 동안 urea 분해 여부를 관찰 결과 20 주 모두가 음성 으로 나타났다. Urease 양성인 T. mentagrophytes와 음성인
Table 3. Results of slide culture on Sabouraud Dextrose Agar

\begin{tabular}{lccc}
\hline \hline \multirow{2}{*}{$\begin{array}{l}\text { Microscopic } \\
\text { features }\end{array}$} & \multicolumn{3}{c}{ T. verrucosum var } \\
\cline { 2 - 4 } & $\begin{array}{c}\text { album } \\
(\mathrm{n}=17)\end{array}$ & $\begin{array}{c}\text { ochraceum } \\
(\mathrm{n}=2)\end{array}$ & $\begin{array}{c}\text { discoides } \\
(\mathrm{n}=1)\end{array}$ \\
\hline Microconidia & - & - & - \\
Macroconidia & - & - & - \\
Chlamydospores & +++ & + & + \\
\hline
\end{tabular}

Table 4. Results of urease test and hair perforation test

\begin{tabular}{lccccc}
\hline \hline \multirow{2}{*}{ Colony type } & \multicolumn{2}{c}{ Urease test } & & \multicolumn{2}{c}{ Hair perforation } \\
\cline { 2 - 3 } \cline { 5 - 6 } & + & - & & + & - \\
\hline $\begin{array}{l}\text { T. album } \\
(\mathrm{n}=17)\end{array}$ & - & 7 & & - & 17 \\
$\begin{array}{l}\text { T. ochraceum } \\
(\mathrm{n}=2)\end{array}$ & - & 2 & & 2 & - \\
$\begin{array}{l}\text { T. discoides } \\
(\mathrm{n}=1)\end{array}$ & - & 1 & & 1 & - \\
\hline Total & 0 & 20 & & 3 & 17 \\
\hline
\end{tabular}

T. rubrum 을 대조균으로 같이 사면배지에 접종하여 음성 과 양성을 감별하였다(Fig. 3 \& Table 4).

\section{고 찰}

동물친화성 진균인 T. verrucosum 감염은 동절기를 중심 으로 늦가을부터 봄에 많이 발생하며 감염요인으로는 소 의 연령, 면역, 영양상태와 사육환경이며 주로 축사내부 의 환기, 습도, 그리고 집단 사육 등이 위생적이지 못할 


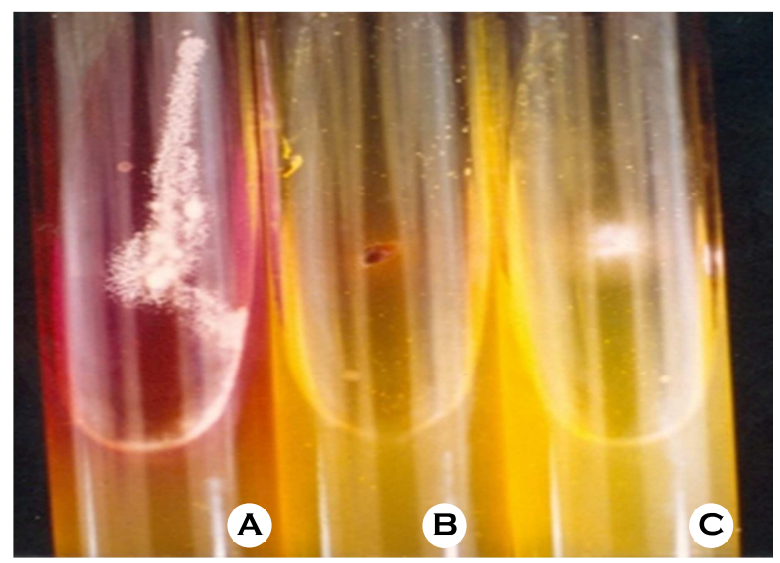

Fig. 3. Urease test. A: T. mentagrophytes (positive control), B: T. rubrum (negative control), C: T. verrucosum (-)

경우 나타나며 이로 인해 감염된 소를 사육하거나 접촉하 였을 때 인체유발을 일으킨다(Choe et al., 2006). 소의 감염 초기에는 작은 회백색의 반점으로 시작하여 탈모가 시작 되며 탈모의 직경이 $1 \sim 10 \mathrm{~cm}$ 정도로 커지고 탈모부위에 는 둥글고 딱딱한 가피가 형성된다(Kim et al., 2002; Hong et al., 2018).

T. verrucosum 의 분류는 Sabouraud가 maltose 배지에서 황토색의 착색을 나타내는 T. ochraceum, T. album 및 $T$. discoides에 대하여 기술하였고 1934년 Emmons 등은 T. verrucosum의 포자와 부속기관의 형태에 따라 분류하였으 며 T. album, T. ochraceum, 그리고 T. discoides와 같은 균주 임을 보고하였다(Emmons, 1934; Lü, 1961). T. verrucosum은 형태에 따라 실온 배양 시 집락의 성장이 매우 느리고 공중균사가 적고 융기된 집락의 모양이 흰색의 단추모 양을 한 것을 $T$. album 형, 편평한 황색을 띄는 집락을 $T$. ochraceum 형 그리고 편평하고 공중균사가 다소 나타나며 연한 회색의 집락을 나타내는 T. discoides 형으로 세 가지 로 분류되었다(Choi et al., 1979). 최 등(Choe et al., 2006)의 19년간 T. verrucosum 감염증의 후향적 관찰에 의하면 소 에서는 주로 안면, 눈 주위, 두부 등의 부위에 희고 두꺼 운 가피성 인설과 탈모반으로 나타나며 감염된 소로부터 인체 감염 시 병변 전체에 염증과 삼출이 심한 융합성 원 형 판 및 두부 독창으로 나타난다(Choe et al., 2006). 김 등 (Kim et al., 1992)은 T. verrucosum은 실온에서 3 4주 배양 할 경우에 집락의 크기가 $10 \sim 15 \mathrm{~mm}$ 정도라고 하였으며 이러한 성장속도가 느리므로 적어도 4주간 배양하여 집 락을 관찰하여 동정이 가능하나 오염으로 분리 동정이 쉽
지 않아서 본 균에 의한 감염증의 실제 빈도는 더 높을 가능성을 보고하였다(Kim et al., 1992).

대부분의 피부사상균은 $25^{\circ} \mathrm{C}$ 에서 배양하는 것을 원칙 으로 하며 $37^{\circ} \mathrm{C}$ 에 배양하면 집락의 성장이 억제되고 착 색이 잘 나타나지 않는 반면 T. verrucosum은 $25^{\circ} \mathrm{C}$ 보다 $37^{\circ} \mathrm{C}$ 에 배양하면 잘 성장하는 특징이 있다(Choi and Lee, 2006; Choe et al., 2006).

본 연구진도 앞선 논문의 실험 성적을 비교하기 위하 여 실험조건을 $37^{\circ} \mathrm{C}$ 에서 실시하였다(Choi and Lee, 2006; Choe et al., 2006). SDA 평판배지에서 집락의 크기를 관찰 한 결과 1 주 평균 $5 \mathrm{~mm}, 2$ 주에는 평균 $33 \mathrm{~mm}, 3$ 주에는 평균 $42 \mathrm{~mm}$, 그리고 4 주 후에는 평균 $58 \mathrm{~mm}$ 로 나타났다. 본 실험에서는 집락의 형태를 관찰하기 위해 $\mathrm{SDA}, \mathrm{PDA}$ 배지에 접종하여 배양한 결과 두 배지간의 집락 소견과 현미경 소견은 큰 차이가 없었다. 집락의 형태를 보면 중 앙부에서 시작되는 굵은 방사상의 주름이 보이는 T. album 형이 $17(85 \%)$ 균주, 집락의 전반에 걸쳐 미세 주름이 있 는 T. ochraceum 형이 2 (10\%)균주, 성장속도가 빠르고 주 름이 없으며 흰색의 솜털모양 T. discoides 형이 $1(5 \%)$ 균 주로 나타났다.

이 등(Lee et al., 1991)은 소에서 분리한 T. verrucosum 총 56균주에서 T. album 형이 28 (50\%)균주, T. ochraceum 형이 16 (25.6)균주, 그리고 T. discoides 12 (21.4\%)균주로 나 타났기에 본 실험과 분리율에서 차이가 있음을 확인하였 다(Lee et al., 1991).

최 등과 이 등의 T. verrucosum의 현미경 소견은 대부분 의 논문에서 균사와 후막포자가 생성됨을 보고하였으나 대분생자와 소분생자의 생성은 관찰할 수 없었다고 하였 다(Lee et al., 1991; Choe et al., 2006). 이에 본 실험에서도 $\mathrm{SDA}$ 및 $\mathrm{PDA}$ 배지에 접종하여 배양된 집락을 Scotch tape method와 Slide culture로 관찰한 결과 대분생자와 소분생 자의 생성은 관찰할 수 없었고 균사와 T. verrucosum 동정 에 중요한 소견인 사슬모양의 후막포자는 T. album 형에 서만 볼 수 있고 다른 형에서는 균사 끝에 단일성 후막 포자만 볼 수 있었다.

T. verrucosum에 대한 모발천공 시험은 많지 않으며 이 등은 소에서 분리한 3 균주를 실험한 결과 모두 음성이었 다(Lee et al., 1991). 김 등은 사람에게 분리된 30균주를 모발천공 검사를 실시한 결과 30 균주 모두가 양성이었고 urease test에서도 11균주가 양성이었다(Kim et al., 1992).

본 연구진에 의한 모발천공 검사는 모발천공 양성이 3 (15\%)균주이며 이 중 2균주는 T. ochraceum 형이고 1균주 
는 T. discoides로 조사되었다. Urease 시험에서 20균주는 모두 음성으로 조사되었다.

이 연구에서 동물친화성인 T. verrucosum이 동물과 사람 에서 분리되었을 때 모발천공 검사와 urease 시험 결과가 다소 차이가 있음을 확인하였기에 이 연구는 향후 동물 친화성 진균인 T. verrucosum의 변화추이에 기초자료가 될 것으로 생각된다.

이 논문에서 저자는 강원도 횡성의 한우 농가에서 소 버짐이 있는 한우에서 분리한 T. verrucosum 의 진균학적 성상을 관찰하였다. 소에서 분리한 20 균주의 T. verrucosum 를 $\mathrm{SDA}, \mathrm{PDA}$ 배지에 배양하여, 균주의 특징을 육안적으 로 집락을 관찰하고, 현미경 소견, 모발천공 시험, urease 시험을 통해 확인하였다.

$37^{\circ} \mathrm{C}$ 에서 $\mathrm{SDA}$ 평판배지에 배양하여 관찰한 결과 집락 의 크기는 1 주 평균 $5 \mathrm{~mm}, 2$ 주에는 평균 $33 \mathrm{~mm}, 3$ 주에는 평균 $42 \mathrm{~mm}$, 그리고 4주 후에는 평균 $58 \mathrm{~mm}$ 로 나타났다. 집락의 형태를 살펴보면, 중앙부에서 시작되는 굵은 방사 상의 주름을 보이는 T. album 형이 17균주, 집락의 전반에 걸쳐 미세 주름이 있는 T. ochraceum 형이 2균주, 성장속 도가 빠르고 주름이 없으며 흰색의 솜털모양 T. discoides 형이 1 균주가 분리되었다.

$\mathrm{SDA}$ 및 $\mathrm{PDA}$ 배지에 접종하여 배양된 집락을 현미경 으로 관찰한 결과 T. verrucosum 균주에서 대분생자와 소 분생자는 관찰되지 않았고, 균사와 후막포자는 T. album 형에서만 볼 수 있었다.

T. verrucosum 20균주를 대상으로 모발천공 검사 결과는 양성은 3균주, urease 시험에서는 20주 모두에서 음성으로 나타났다.

\section{ACKNOWLEDGEMENT}

None.

\section{CONFLICT OF INTEREST}

The authors have no conflict of interest to declare.

\section{REFERENCES}

Bang YJ, Kim SY. Epidemiologic investigation of onychomycosis and Tinea pedis in children. Korean J Clin Lab Sci. 2007. 39: 91-95.
Choe YS, Park BC, Lee WJ, Jun JB, Suh SB, Bang YJ. The clinical observation of Trichophyton verrucosum infections during the last 19 years (1986 2004). J Mycol Infect. 2006. 11: 45-53.

Choi CP, Lee MH. Six cases of Tinea capitis in adults. Korean J Med Mycol. 2006. 11: 31-35.

Choi WP, Yeo SG, Lee HB. Studies on Dermatophytosis of Korean cattle. Korean J Vet Res. 1979. 19: 149-152.

Emmons CW. Dermatophytes: natural grouping based on the form of the spores and accessory organs. Arch Dermatol Syphilol. 1934. 30: 337-362.

Hong JS, Lee DW, Suh MK, Ha GY. Macroscopic and microscopic findings of Trichophyton verrucosum isolated from cattle. J Mycol Infect. 2018. 23: 118-119.

Kim BG, Oh CK, Jang HS, Kwon KS. A case of kerion on the thigh due to Trichophyton verrucosum. J Mycol Infect. 2002. 7: 161-164.

Kim HJ, Jang HC, Lee SW, Chung H, Jun JB. A case of neonatal Tinea capitis. Korean J Med Mycol. 2006. 11: 195-198.

Kim JC, Choi JS, Kim KH, Suh SB. Mycological features of Trichophyton verrucosum isolated in Taegu area. Ann Dermatol. 1992. 30: 761-768.

Kim YP, Chun IK, Kim SH. A Case of Kerion Celsi Caused by Trichophyton verrucosum and Its Epidemiologic Study. Ann Dermatol. 1986. 24: 687-691.

Lee HJ, Choo SW, Choi WP. Epidemiological and Mycological Studies on the Bovine Dermatophytosis J. Prev Vet Med. 1991. 15: $247-253$.

Lee HJ, Kim SM, Eun DH, Lee WJ, Bang YJ, Jun JB. Changes in the clinical and epidermiological characteristics of Trichophyton verrucosum infection. J Mycol Infect. 2018; 23: 99-104.

Lü YC. A new method for the study of hair digestion by Dermatophytes. Mycopathol Mycol Appl. 1961. 17: 225-235.

Shin DH, Kim KS, Kim KH. Clinical and mycologic studies of Tinea capitis in Taegu. J Mycol Infect. 1998. 3: 132-138.

Zhan P, Liu W. The Changing Face of Dermatophytic Infections Worldwide. Mycopathologia. 2017. 182: 77-86.

https://doi.org/10.15616/BSL.2019.25.4.367

Cite this article as: Kim SJ. Mycological Features of Trichophyton verrucosum Isolated in Cattle. Biomedical Science Letters. 2019. 25: 367-371. 